\title{
From Cryptozoology to Conservation Biology: An Earlier Baseline for Entanglement of Marine Fauna in the Western Pacific Revealed from Historic “Sea Serpent" Sightings
}

\author{
Robert L. France \\ Department of Plants, Food and Environmental Science, Dalhousie University, Nova Scotia, Canada \\ Email: rfrance@dal.ca
}

How to cite this paper: France, R. L. (2020). From Cryptozoology to Conservation Biology: An Earlier Baseline for Entanglement of Marine Fauna in the Western Pacific Revealed from Historic "Sea Serpent" Sightings. Advances in Historical Studies, 9, 4569. https://doi.org/10.4236/ahs.2020.92005

Received: May 10, 2020

Accepted: June 27, 2020

Published: June 30, 2020

Copyright $\odot 2020$ by author(s) and Scientific Research Publishing Inc. This work is licensed under the Creative Commons Attribution International License (CC BY 4.0).

http://creativecommons.org/licenses/by/4.0/

Open Access

\begin{abstract}
Marine conservation biologists have increasingly acknowledged the value of non-traditional sources such as historical anecdotes for providing useful information about past conditions of social-ecological systems as part of a comprehensive management strategy for recognizing and setting trajectories toward re-establishing baseline conditions. The present study demonstrates that careful parsing of eyewitness accounts of unidentified marine objects (UMOs), which at the time had been purported to be sea serpents of the "many-humped" or "string-of-buoys" typology, reveals that marine animals in the Western Pacific have been victims of non-lethal entanglement in fishing gear for much longer than is commonly believed. The temporal baseline for onset of entanglement in this region certainly predates the mid-twentiethcentury use of plastic in fisheries and other maritime operations.
\end{abstract}

\section{Keywords}

Unidentified Marine Objects, Fishing Gear Entanglement, Nineteenth Century, Western Pacific

\section{Introduction}

Historical information is deemed essential to "answer questions about trends, rates of change, tipping points, safe operating spaces and pre-impact conditions" in complex social-ecological systems (SESs) (Dearing et al., 2015). In particular, conservation biology benefits from inclusion of such temporal information in order to ensure its interpretations are sound and its proscriptions meritorious 
(Meine, 1999; Szabo \& Hedl, 2011). One of the challenges faced in marine historical ecology is being able to back-cast the period of reference from which to detect the onset of deleterious change (Engelhard et al., 2016). Given the rarity of temporal consistency among quantitative metrics such as species abundance, qualitative variables can serve as surrogates of Anthropocene alterations. Dearing et al. (2015), for example, show how archival documents can be used to reconstruct integrated regional histories about landscapes, ecosystems, and resources.

Historical ecology and ethnobiology (e.g. Da Silva et al., 2014; Alexander et al., 2017) can help address the conundrum marine biologists face posed by the "shifting baseline syndrome," wherein successive generations redefine that which is considered as "natural" based on their own temporally truncated mindset and casual acceptance of a progressively depauperate natural world as the new norm (McClenachan et al., 2012). Pauly (1995), the first to popularize the concept, championed the value of information contained within antecedent anecdotes for assessing shifting baselines in fisheries. As reviewed by Schwerdtner Manez et al. (2014), this approach has become widely accepted given that "witness testimonies, especially, are increasingly used to acquire information on past and contemporary marine environments and fisheries." In this light, marine scholars conducting archival research have imaginatively mined anecdotal information from non-traditional sources, including explorers' reports, travelers' diaries, naturalists' journals, fishers' observations, ethno-historic records, and museum documents (e.g. SaenzArroyo et al., 2005; Saenz-Arroyo et al., 2006; Johannes \& Neis, 2007; Al-Abdulrazzak et al., 2014; Marschner et al., 2014; Early-Capistran et al., 2018; Bargnesi et al., 2020). It is within this emerging scholarly field of historical ecology fused with ethnozoology that the present study is situated through its examination of anecdotal evidence for the early entanglement of marine fauna in the Western Pacific as revealed from early "sea serpent" sightings in the region.

In his comprehensive history of the North American fishery, Bolster (2012: p. 91) asserted that "no marine environmental historian worth his or her salt can afford to ignore... nineteenth-century sea serpents." Indeed, eyewitness accounts of sea monsters have proven a rich source of insight about the history of humannature relationships during the nineteenth century (e.g. Brown, 1990; Lyons, 2009; Paxton \& Shine, 2019). For example, the careful parsing of the words contained within anecdotes of unidentified marine objects (UMOs), purported at the time to have been sea serpents, generates data (sensu Paxton, 2009) of relevance to concerns of contemporary conservation biologists (Parsons, 2004). In particular, textural records by eyewitnesses of UMOs provide information that marine animals have been subjected to anthropogenic pressure, not just from direct fishery mortality, but also as a consequence of non-lethal entanglement in fishing gear (France, 2018; France, 2019a; France, 2019b; France, 2019c; France, 2020).

A handful of UMO sightings that occurred within the Western Pacific went on to garner worldwide attention, but which from the anecdotal descriptions 
and accompanying illustrations by eyewitnesses, are likely to have really been animals entangled in pre-plastic fishing gear (France, 2016a; France, 2016b; France, 2017). The purpose of the present investigation was to expand examination of the entire corpus of UMO sightings from the Western Pacific to include those from over more than a century and irrespective of the deduced type of animal, to see if compelling evidence exists for the widespread incidence of inferred non-lethal entanglement in the region. Accomplishing this would indicate that entanglement has a much longer environmental history than is commonly believed, and would provide another example of how anecdotal research (Pauly, 1995) can contribute toward recognizing past fishery pressures. This information would in turn be useful for developing a more complete understanding of baseline shifts in affected populations, contributing thereby towards the global marine historical research initiative (Schwerdtner Manez et al., 2014).

\section{Methods}

\subsection{The Study Region}

The substantial threat posed to Western Pacific megafauna by becoming entangled or through succumbing to incidental bycatch has been recognized for several decades (e.g. Wright \& Doulman, 1991; Richards, 1994; Boren et al., 2006; Gregory, 2009; Jaaman et al., 2009; Wilcox et al., 2014; Edyvane \& Penny, 2017; Tulloch et al., 2019). It is the present contention that given the history of extensive fishing in this region long before colonization by the British and Frenchthe two nationalities responsible for the bulk of the sea serpent sightings during the nineteenth and twentieth centuries-neither entanglement nor bycatch are unlikely to be new phenomena.

Fishing equipment has been cast, set, or dragged within the waters of the Western Pacific for millennia (e.g. Kuang-Ti, 2001; Ono \& Intoch, 2011; O'Connor et al., 2011; Anderson, 2013). In more recent times, the deployment of purse seines, long-lines, trawls, and driftnets for subsistence activities by coastal villages was expanded to supply remote markets by the end of the nineteenth century (e.g. Klaer, 2001; Tilzey et al., 2001; Butcher, 2004; Morgan \& Staples, 2006; Novaglio et al., 2019), well before the onset of international exploitation and the industrialization of fisheries, dependent as both were upon the use of synthetic material in the middle of the twentieth century.

The working premise herein is that, if Alverson et al. (1994) and a senior NOAA scientist interviewed by Deedy (2017) are correct, and bycatch and non-lethal entanglement have existed ever since fishing began and humans first hurled spears and floats into the waves and set nets in the water (Fagan, 2017), then it should be possible to detect their presence hidden in the anecdotes of historical sightings of misconstrued sea serpents.

\subsection{The Anecdotal Provenance}

The historical source mined for anecdotes was the authoritative text of Heuvel- 
mans (1968), recognized for its comprehensive listing of sea serpent sightings compiled from hundreds of disparate sources such as newspaper reports, magazine articles, and scientific journal papers, in addition to those incorporated from the earlier seminal compendium of Oudemans (1892). From the complete corpus of 70 sightings reported from the Western Pacific region between 1820 and 1966, a subset of 28 accounts were selected based on a coded survey of their UMO descriptions suggesting the observed UMOs to have been animals that were non-lethally entangled in fishing gear. Excerpts from the longer anecdotes are presented herein, divided and diachronically arranged within each of the three regions of Australasia, Indochina (as Southeast Asia was then referred to by Europeans), and Indonesia. Following established tradition when reviewing sea serpent sightings, a composite cryptid is assembled from the anecdotal descriptions. In no way should this fusion be interpreted as implying that these geographically distinct and temporally separated sightings correspond to the same individual or even species of entangled animal being misconstrued as a "sea serpent." Instead, this summarizing approach merely provides a convenient manner in which to compare salient characteristics of the generic UMO for the Western Pacific with those derived similarly for the Gloucester Sea Serpent (France, 2019a) and UMOs in other geographic regions (France, 2019c; France, 2020).

\subsection{The Precedent for Comparison}

The illation that a proportion of the sightings of "sea serpents" from the Western Pacific were really observations made of animals entangled in fishery equipment that went unrecognized at the time, derives from a careful examination of the so-called "Gloucester Sea Serpent" which frequented New England and New York during the early nineteenth century. This particular theory has been endorsed by scientific experts and knowledgeable commentators as being a particularly meritorious explanation for many UMOs (Deedy, 2017; www.gloucesterseaserpent.com).

The Gloucester UMO sightings are unique given that most sightings of so-called sea serpents are made by a single eyewitness and occur for only a brief duration (Oudemans, 1892; Heuvelmans, 1968). The Gloucester UMO, however, was repeatedly observed by hundreds of people over a period of months (O'Neill, 1999; Soini, 2010), and is the most sighted "sea serpent" in history (France, 2019a). Consequently, the UMO cannot be dismissed as the delusions of a few, as for example, was the case for the witches of Salem and the devils of Loudon. Clearly, what the people saw in the water was something that was atypical to the norm, and it is this which led to the ensuing social phenomenon (Burns, 2014). A second unique feature of the Gloucester UMO is that it remains the most thoroughly investigated "sea serpent" of all time through the comprehensive study pursued by the Region's learned natural history society (France, 2019a). Furthermore, the UMO went on to play an important role in the genesis of American natural science and in international discussions about the theory of evolu- 
tion (Brown, 1990; Lyons, 2009). And it is for these reasons that the Gloucester Sea Serpent is exalted by cryptozoologists for providing "by far the best-documented evidence that sea-serpents exist" (Bauer, 2013). The irony comes from the fact that the Gloucester UMO does the exact opposite through being the hallmark for concluding that some so-called sea serpents, particularly those repeatedly referred to as the "many-humped" or "string-of-buoys" variety, were in fact actually animals pulling entangled fishing gear or other maritime debris (France, 2016a, 2016b, 2016c, 2017, 2019c, 2020).

The evidence that the Gloucester UMO was an entangled animal is extremely compelling (France, 2019a; www.gloucesterseaserpent.com) based on the frequent descriptions made of its body resembling a string of herring net floats or casks tied together and lying upon the surface of the water (Table 1); i.e. the so-called "duck test" of abductive reasoning. Other morphological and behavioral characteristics which also bespeak entanglement include bodies: 1) of unusual length described as being extremely flexible and moving through vertical undulations, often accompanied by notable disturbance of the water; or, 2) if stationary, being composed of distinct components floating upon the surface of the water for considerable periods before suddenly being pulled down; and 3) being serpentine in shape and sporting a mane or horns and spikes, while displaying a

Table 1. Descriptions of the unidentified marine object (UMO), imagined to be a sea serpent, observed between 1815 and 1824 in Gloucester Harbor and elsewhere in New England and New York, and clearly indicative of a marine animal that was non-lethally entangled in fishing gear or other maritime debris (France, 2019a; France, 2019c).

“...his appearance in this situation was like a string of buoys. I saw perhaps thirty or forty of those protuberances and bunches, which were about the size of a barrel."

“...looked like the buoys of a seine"

“...with a good glass [I saw what] seemed like gallon kegs tied together”

"His body when out of the water looks like the buoys of a net, or a row of kegs, or a row of large casks"

“...of the size of a barrel about the body, which... are so prominent, that they resembled buoys attached to each other"

"[The body] appears in joints like wooden buoys on a net rope almost as large as a barrel, that the musket balls appear to have no effect on it, that it appears like a string of gallon kegs.”

“....as he moved he looked like a row of casks following in a right line"

"He appears to be full of joints and resembles a string of buoys on a net rope, as is set in the water to catch herring. Others describe him as like a string of water casks... Two [musket] balls were thought to hit his head, but without effect."

“...resembled the link of a chain."

"The first view I had of him appeared like a string of empty barrels tied together, rising over what little swell of the sea there was."

"The back was composed of bunches about the size of a flour barrel, which were apparently about three feet apart...and looked like a string of casks or barrels tied together."

"The body, which is formed into parallel rings, which—when he is on the top of the water-are so prominent, that they resembled buoys attached to each other."

“.... and to seem jointed, or like a number of buoys or casks following each other in a line.”

“...the curvature and bunches on his back. To some he appeared jointed, or like a string of kegs or buoys connected on a rope."

"...giving the appearance of a long moving string of corks." 
peculiar obliviousness of surroundings or an imperviousness to physical disturbance (France, 2019a). It is important to remember all these attributes of the Gloucester UMO when reading through the following accounts of UMOs from the Western Pacific.

\section{Results}

\subsection{Australasia}

In 1870, off Nepean Island in the Tasmin Sea, a 10-metre long and extremely narrow third-of-a-metre wide "veritable Sea Serpent" was spotted [Anecdote 1]: "When first seen, I suppose it must have been asleep, for its head was lying flat on the surface of the sea, and its body coiled up" (Heuvelmans, 1968: p. 251). It was concluded that as the animal was able to "coil up on itself and showed no feet," it was a "true serpent."

While walking along a beach at Géographe Bay on southwest tip of Australia in 1879 , several people sighted a 20 -metre long UMO, as subsequently reported in the journal Nature. The creature was "straight and taper[ed], like a long spar, with the butt end, his head and shoulders, showing well above the surface... [and with a head like that] of the end of a log... about two feet in diameter" [Anecdote 2] (p. 281). Neither lateral fins nor a caudal bilobate tail were noted, but the back of the UMO was described as being divided into a series of distinct compartments, as shown in an illustration (Figure 1(a)).

Around this time a "maned" UMO was seen near the barrier reef of New Caledonia [Anecdote 3]. And in 1899, a steamer pulled into Sydney and exhibited the body of an UMO that was described as being "covered with hair" [Anecdote 4].

Off the North Island of New Zealand in 1891, the crew of a steamer saw an UMO with "two armlet appendages of great length, which appeared to dangle about like a broken limb on a human body" [Anecdote 5] (pp. 302-303). When the creature suddenly plunged into the water, the strange "appendages" were sent "scattering in all directions." Seen again the following week by several people aboard another ship, the UMO's "shape was for all the world like a huge conger eel, with the exception that it had two large fins that appeared to be about 10 feet long." These eyewitnesses went on to note that "the creature's head did not appear to be particularly definite, the neck running right up to the head the same as that of a large eel." In 1898, "a great splash" caught the attention of several people on a New Zealand shoreline. An UMO was seen that had "the tail of some fish... [and] a long, thin body attached to it," which was thrown upwards [Anecdote 6] (p. 365). One eyewitness stated that: "I should say that the body attached to the tail was about eighteen inches in diameter by the tail, and thickened to two feet or more about 12 to 16 feet from the tail, which was about the height it came up above the sea," before going on to comment that part of the UMO looked like a bottle-nosed whale. Heuvelmans, however, asks the pertinent question: "but how could any known cetacean raise 10 feet of thin and cylindrical 


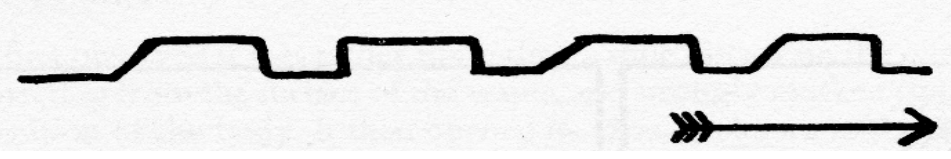

(a)

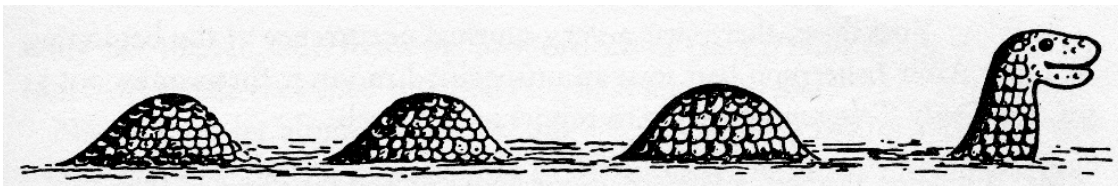

(b)

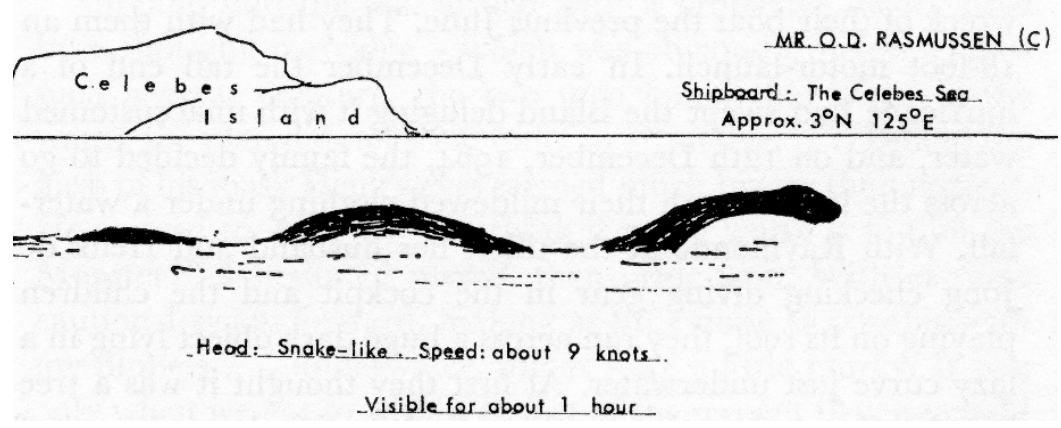

(c)

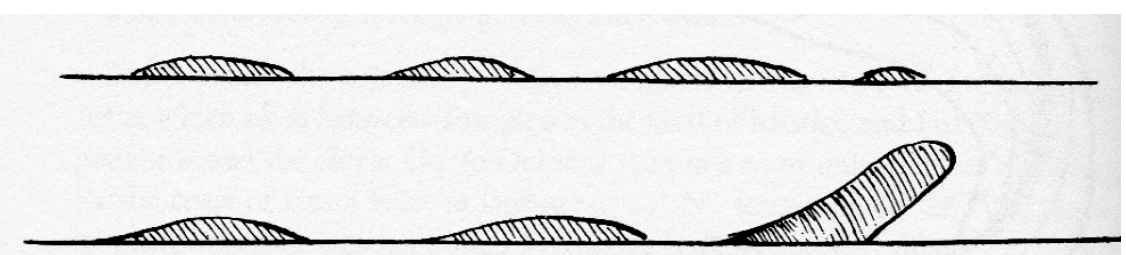

(d)

Figure 1. Cryptozoology or conservation biology in the Western Pacific? Unidentified marine objects seen (a) in Géographe Bay, Australia in 1879; (b) on the Great Barrier Reef, Australia in 1934; (c) in the Indonesian Celebes Sea in 1961 (Dinsdale, 1966); and (d) west of Sumatra in 1928, and interpreted as either being the "many-humped" or "string-of-buoys" variety of sea serpents (Heuvelmans, 1968) or actual strings of fishing net buoys pulled behind entangled animals (This paper: Anecdotes 2, 12, 26, and 28). (From Heuvelmans, In the Wake of Sea-Serpents, 1968; and Dinsdale, The Leviathans, 1966. Author's private collection.).

body out of the water?"

Two years later, an UMO was seen off Cape Naturaliste, Western Australia [Anecdote 7] (p. 366). It is described as "a rubbery worm-like animal some 300 feet long and 3 feet in diameter, which rose out of the water in three huge arches in a way that was both mechanically and dynamically utterly impossible. In front of these arches a head rose on the end of a long neck, and on the spine was a sort of high soft fin that could fold up like a parasol." Heuvelmans gives no credence to the supposition by the editor of the magazine where the report was originally published that the animal was a gigantic octopus, but is at a loss to explain it himself as the UMO did not fit into any of his own imagined categories of sea monsters. In 1902, on the other side of the country, the crew of a ship saw a 
10-metre long UMO which had "four fins 4 to 5 feet high and about 6 feet apart" [Anecdote 8] (p. 367). The "fins" were described as being angular in shape. In the same region in 1925, the crew of a steamer progressing between Brisbane and Sydney noted a "violent disturbance" in the water and observed an 8-metre long UMO whose body was described as being cylindrical and which "seemed to have a long head" that would fall back into the water with a "loud splash" [Anecdote 9] (p. 410-411). Then, "when the animal feel back, a fin about 12 feet long rose at an angle on the right side behind the head, and the body curved to this side when it fell. At the same time there rose out of the water, several feet away, a sort of tail, much thinner than the front part...The erected 'fin' was much lighter [in colour] still: almost white with black patches." Later that year on the east coast of Australia, eyewitnesses recorded seeing "a fantastic apparition" for fifteen minutes which had a big head on a long flexible neck. Behind this was a body "as thick as the big Bordeaux barrels, formed a chain of five loops; on the fourth loop, an aileron as on sharks of large dimensions, measuring 5 feet in height and in width at the base...As it passed astern of the ship and was abeam of the starboard screw, the animal's head began to move backwards and forwards, which led us to think it had been touched by a blade of the screw; its movements seemed hindered and was not at all like that of the little snakes seen near the coast" [Anecdote 10] (p. 427). Asian crew members aboard cried out "There's the Dragon!," with one apparently making an offering to the beast.

Eyewitnesses in New Caledonia in 1929 first thought they had spotted a sea turtle or dugong until such time as "a third dark spot appeared above the surface, travelling immediately behind the first; then yet more of these humps broke water and at the same time the first one uprose, revealing a typical snake's head supported on the usual serpentine neck and form. On seeing this we realized immediately that we were looking at a giant water-snake" [Anecdote 11]. As the UMO leisurely swam past, "coil upon coil of its great [20-metre] length kept protruding out of the water; its head was darting to and fro as though searching for something, then, on sighting a shoal of mullets, it plunged after them at great speed, and finally disappeared amongst them amid a deal of splashing" (p. 429). The observer noted that there had been numerous accounts from the region of huge sea snakes exceeding 25 metres in length with columnar bodies, some of which sported "a mane of hair." Heuvelmans correctly recognizes the dilemma posed by this and similarly described cryptids wherein the oft-described vertical undulating movement is completely contrary to the horizontal flexature by which means sea snakes actually swim.

On the Great Barrier Reef in 1934, four objects were observed moving in a line in the water [Anecdote 12] (Figure 1(b)). The UMO had a "huge turtle's head" and "the other part in view was three curved humps about 20 feet apart, and each one rose from 6 feet in the front to a little less in the rear. They were covered in barnacles. We could not get a glimpse of the tail, as it was under the water" (pp. 454-455). Another eyewitness mentioned that the UMO was "floating 
motionless on the water" and had "a dark line along its spine. The scales shone in the sun and seemed to be 'butted [i.e. affixed together as in a carpentry butt-joint] and perpendicular'. Some of the barnacles were as big as soup-plates.” Other sightings over the period of several weeks stated the UMO to be 10 metres long and to have made a loud noise when swimming, with a "body [that] was like 'a huge armoured hose'." One described it as a "monster of the sea with a series of humps." Heuvelmans comments that the illustration "looks as if it belongs in a mediaeval bestiary or a cartoonist's album," and that the statement of the cryptid being like an armoured hose implies it to have been a "cetacean centipede." Also, as the biggest barnacles are only several inches in diameter, he remarks that the soup-plate sized barnacles "would be unknown monsters themselves." He goes on to state that the "oddest thing about...[the] account is that the scales on the humps run in horizontal rows," which he is correct to point out "is quite impossible in any animal that must bend." The conclusion reached is that "if the monster was really humped and scaled as he has depicted it, it is quite unlike any other sea-serpent, let alone any animal known to science."

In 1955, two eyewitnesses near Darwin on north coast of Australia saw a rapidly moving 30-metre long UMO that "showed a series of humps which rose and fell on the surface as it swam" [Anecdote 13] (p. 505). In same region four years later, another 30-metre long UMO with a body that "shone with green flashes" was described as swimming at "staggering speed" "above the water" [Anecdote 14] (p. 505). Some eyewitnesses thought it could be a giant manta ray, but the mystery that continued to elude everyone, here and well as elsewhere, was how to account for the long extension attached to what might have otherwise been an easily recognizable animal.

Three other, briefly described, sightings of UMOs are worth noting. In 1930 near Sydney, a 25-metre UMO was seen "undulating lazily" with a head held aloft "at the end of a long snake's neck" [Anecdote 15] (p. 431). Three years later, off North Cape in New Zealand, a 50-metre long UMO was seen with a body "as thick as a steamer's funnel" [Anecdote 16] (p. 430). And in 1962, at the time when fishing gear was becoming made of synthetic material, a "horrible monster...out of a nightmare" was seen off Queensland coast. The UMO had a long neck described as being covered with a "hairy crest" [Anecdote 17] (p. 506).

\subsection{Indochina}

While in anchorage at Singapore harbour in 1854, the crew of a vessel observed a 20-metre long UMO having "a great resemblance to the boa [snake]" [Anecdote 18]. The mystery animal kept its head raised above the water which caused its "pointed and arched tongue to tremble" (Heuvelmans, 1968: p. 230). The body was described as being composed of two series of "circles or knots on the surface, diapered with patches of black and pale yellow," with one of the series separated from the other and consisting of "coils or rings of which I was able to count eleven, by a prolongation of its majestic body." 
The year 1893 brought the first account of a series of UMO sightings that occurred over a decade in the Vietnamese Gulf of Tonkin. All these sightings from Indochine (as the region was then known to the French) led to a 1904 report to the Academy of Sciences in Paris wherein the statement was made that "the sea-serpent has emerged from legend and entered reality...We may suppose that the sea-serpent belongs to those groups thought to be extinct, for instance the Mososaurs or Ichthyosaurs" (p. 351).

The first sighting briefly described a long black UMO seen "swimming by vertical movements" [Anecdote 19] (p. 344). Four years later, "two animals of weird shape and large dimensions [22 metres long and 2 - 3 metres in diameter] ... veritable sea-monsters" were encountered [Anecdote 20]. Eyewitnesses remarked that "the feature of these animals was that their body was not rigid like that of the known cetaceans, but made undulatory movements similar to a snake's, but in a vertical direction" (p. 344).

Three more sightings occurred in 1898. Once again, several UMOs were seen rapidly swimming, and when fired upon, the shots "reached them without seeming to do them the least harm" [Anecdote 21] (pp. 344-345). Seen by more people the following week, the UMO was estimated to be 22 metres in length with a seal-like head and a body "subject to undulations that are sometimes very marked." The so-called undulations (by which the eyewitness means body components) "appear without a break. Until then we might have thought that what we took for them were humps appearing in succession; but from the testimony of all the witnesses doubt is no longer permissible, for, before they appeared, we saw the animal emerging by the same amount all along its length." Moreover, the animal's back was "covered with a sort of saw-teeth which, removes any resemblance to known cetaceans." Heuvelmans opines that earlier attempts to infer that the ridge could have been a mane were misplaced given that the hair of such creatures always "hang[s] down the neck, while this crest is on the back." The eyewitness believed that the frequent appearance of such beasts in this region are responsible for the prevalent legends of dragons (no mention is made of the fact that dragon boat races have occurred in Southeast Asia for several millennia). Another sighting from later in the summer reported an UMO 13 metres long and less than half-a-metre in diameter with a head like a turtle's attached to a very thin neck and the body of a snake [Anecdote 22]. The animal exhibited body scales and moved through undulations. An eyewitness described the UMO, which had been observed at close quarters, as follows: "a round fat body like that of a big whale, then a sinuous [original use of italics] part, not emerging completely, but seemed to join the body to the head. The latter fairly large, continuing the neck, of rather oval shape, and with two gaging holes. Finally a set of dorsal spine-like saw-teeth" (p. 347).

Further south, a ship was riding out a typhoon in 1903 near Da Nang when the crew saw that "a double mass appeared, the length of each part must have been about 25 feet and the distance between them about 18. The bulk of each of 
these coils could be compared to that of a big half-hogshead barrel: a spikey crest gave the coils a quite singular appearance. It all undulated like a snake in motion, and its speed was markedly greater than that of the ship...The colour was 'dirty black'. A few seconds later the animal dived horizontally, churning the water violently" [Anecdote 23] (p. 348).

Once again, the Gulf of Tonkin was the location for several sightings of mysterious sea creatures in 1903. The first was of what had originally been thought to be a large turtle which, upon further examination, was transformed into an UMO: "Shortly afterwards I saw this mass lengthen, and there emerged in succession, in a series of [" 5 or 6 marked"] vertical undulations, all the parts of the body of an animal having the appearance of a flattened snake, which I reckoned to be about a hundred feet long and the greatest diameter 12 to 16 feet" [Anecdote 24] (p. 349). The animal proceeded to dive beneath the ship while displaying a back described as "dark grey with patches of dirty yellow" and skin with a "roughness [that] seemed due to scales rather than hair." The head emitted water vapour and "the rest of the body appeared à fluer d'eau [i.e. floating upon the surface like a flower]." And "a series of vertical undulations were seen running along the body, just out of the water" when the animal moved forward. The next year, a 20-metre long UMO was seen in the same area [Anecdote 25]. From its large mass and exhalation of breath, it would normally have been thought to be a whale, had it not been for the other body parts that were observed. Behind the large anterior part of the beast was attached an elongated section that "seemed to...be of almost the same dimensions all along its length," and which was "almost touching the nearby shore" (p. 349). Because the sinuous part displayed "two large [vertical] coils," the eyewitness supposed that the UMO "must belong to a monstrous eel at least 3 feet in diameter." This was supported by the fact that "nobody saw fins" and that the animal was "awash and moving by vertical undulations."

\subsection{Indonesia}

A "sea monster like a dark-skinned snake" was seen by passengers and crew aboard a ship in the Celebes Sea in 1961. The 23-metre long UMO had "a girth corresponding in size to its length for ["a perfect replica of a land"] snake" [Anecdote 26] (Heuvelmans, 1968: p. 383). The exposed neck "disappeared below water level, but two humps followed, evenly spaced by water in between the three visible parts" (Figure 1(c)). The animal, whose swimming was described as "writhing," left an extensive wake. A similar UMO was seen later in the year by people on a steam-launch near Java. What was first taken to be a twisted tree-trunk was discovered to be an animate UMO with a swan-like neck followed by a 10-metre long tail. At one point the creature crossed the path of the boat and its body was described with "a sort of arch [that] rose out of the water in a semicircle and was the thickness of a man's thigh" [Anecdote 27] (p. 384).

On the other side of the archipelago, west of Sumatra, several eyewitnesses in 
1928 reported seeing what first they also first took to be a big tree-trunk before it moved, leaving behind a notable disturbance in the water [Anecdote 28]. Four humps or "portions" were seen above the surface (p. 412) which "did not look like fins: they shone in the sun, they were smooth and not very arched, and their colour was very like that of a seal. Suddenly there rose out of the water a part which looked like a big round branch, about 2 feet in diameter and 6 feet long and making an angle of $30^{\circ}$ with the sea; the end was rounded (see diagram [Figure 1(d)]). Slowly this part dived under the water again, while the sea became very disturbed. Nothing in particular could be seen on this portion out of the water-nothing the shape of eyes or anything similar." Heuvelmans, coming close to the truth without realizing it, refers to the cryptid as being a typical "string-of-buoys sea-serpent."

\subsection{Assembling the Composite Cryptid}

A notable anatomical feature of the Western Pacific UMOs documented herein is their considerable length, ascribed by eyewitnesses to various sizes, including ten metres or less (anecdotes 1, 8, 12, 23, 27), between eleven and twenty metres (anecdotes 2, 11, 18, 22, 25), between twenty-one and thirty metres (anecdotes $13,14,15,20,21,26$ ), and up to more than thirty metres (anecdotes $7,16,24$ ). Bodies are frequently referred to as being elongated and serpentine in form (anecdotes $1,2,5,6,7,9,11,12,14,16,18,20,22,25,26)$. Tellingly, and most notably, much of the length of the UMOs is composed of an overt series of irregular or uneven body parts in the form of a dorsal ridge or crest (anecdotes 2, 11, 13, $21,22)$, that are often variably described as "humps," "coils," "arches," and the like, and are of variable number, ranging from two to three (anecdotes $3,12,23$, $25,26,27$ ), to four to seven (anecdotes $8,10,24,28$ ), to about a dozen (18). Bodily features are occasionally likened to resembling casks or appearing to be scales (anecdotes 10, 12, 14, 22, 23, 24), and significantly, eyewitnesses frequently remark on the conspicuous presence of long strands of material, often interpreted as being "hair" or a "mane" (anecdotes 3, 4, 17).

A notable behavioral feature of the Western Pacific UMOs is their rapid speed of movement (anecdotes 11, 14, 21, 23), which frequently is accompanied by considerable water disturbance (anecdotes 9, 11, 12, 23, 26, 28). Observations reveal that one elongated UMO displayed itself on the surface of the water with high degree of flexibility (anecdote 1), whereas the body components of many were seen to independently move through vertical undulations $(11,13,14,15$, $19,20,22,23,24,25)$. When not swimming slowly or floating motionless upon the water (anecdotes 1, 10,12,15,18,24), sometimes the extended bodies of UMOs were seen to suddenly disappear beneath the surface or be thrashed about (anecdotes 6, 11, 28). Portions of UMOs observed above the sea surface sometimes seemed oblivious to surroundings, even including when passing right in front of a ship (anecdotes 10, 27), as well as being struck with rifle shot (anecdote 21). Remarkably, in one case (anecdote 25), the body floating upon the sur- 
face was actually seen to touch the shore.

\section{Discussion}

The entanglement of marine biota in fishing gear is recognized to be a serious environmental problem, with more than two hundred species suffering its consequences (Laist, 1997; Butterworth, 2012). Although being bycatch often results in quick mortality, there are numerous instances of non-lethally entangled animals pulling trains of debris over extended distances of thousands of kilometres and prolonged timeframes of months or even years (Johnson, 2005; Nielson et al., 2009; Lyman in NOAA 2014; Anonymous, 2019a; Anonymous, 2019b). This occurs even though debilitations brought about by infected wounds and impeded mobility from rope abrasion and hydrostatic drag will compromise longterm survival (Derraik, 2002).

The common belief is that entanglement is a modern phenomenon corresponding to the advent and widespread use of plastic since the middle of the twentieth century (Wabnitz \& Nichols, 2010; Nelms et al., 2015), and that little or none took place before that time (NOAA, 2014). This is based on the assumption that materials consisting of hemp, cotton, and other fibres will "lose their resilience in usage and if lost or discarded at sea [will] tend to disintegrate quickly" (Gregory, 2009). As a result, only in the mid-1980s did ecologists begin to recognize the entanglement threat posed by antrhopogenic debris (Vegter et al., 2014). In their own comprehensive review, NOAA (2014) also found few articles on early, pre-plastic entanglement, opining that "the absence of entanglement records prior to 1950 could be from the low use of synthetic materials in fishing practices and land-based products." Reviews documenting the history of entanglement are consequently limited to covering only the last few decades (e.g. Groom \& Coughran, 2012; Reeves et al., 2013; Balzas in NOAA, 2014).

In reality, although it is certainly true that earlier ropes and nets made from natural fibre would have deteriorated more rapidly than their modern-day synthetic equivalents, it is erroneous to suppose that such materials were not of sufficient durability as to justify their ubiquitous and continued maritime use (McCaskill, 2009), nor their consequent ability to pose an entanglement threat to susceptible wildlife. Hemp is known to become "stronger when wet and does not rot easily in water" (Aiken \& Purser, 1936). Moreover hemp ropes were customarily impregnated with tar or reinforced with wire to extend their longevity (Kristjonsson, 1971; Bekker-Nielsen \& Casola, 2001; Cardamone 2001), with manila hemp rising in popularity throughout the nineteenth century in consequence of containing natural oils that accomplished the same preservation (Goode et al., 1884; Wilcocks, 1884). Treated with preservatives, natural fibre ropes have a longevity of more than a year (Aiken \& Purser, 1936). As a result, it is easily conceivable that early non-lethal entanglement could have lasted for periods of many months. This is more than enough time for unfortunate animals pulling 
long trains of anthropogenic debris-including net buoys, which during the nineteenth century, were blown-glass balls, cork floats, or wooden casks-to be observed and misconstrued as the archetypical form of the "many-humped" or "string-of-buoys" sea serpent (sensu Heuvelmans, 1968). Several examples of such UMOs have been previously noted from the Western Pacific.

The chelonian-like UMO that was seen in the Malacca Strait in 1876 (Oudemans, 1892) was attached to what was imagined to have been an immense 50metre long cylindrical tail that bobbed up and down on the surface of the water (Figure 2(a)), but which was probably a string of fishing floats (France, 2016b). In 1879, the whale observed in the East China Sea which was thought to be engaged in a fierce battle with a long serpentine creature affixed to its right fin (Figure 2(b); Heuvelmans, 1968), was no doubt an unfortunate cetacean struggling to free itself from a train of fishing gear (France, 2016a). The bizarre chimeric "moha-moha" creature seen on a Queensland beach in 1890 was almost certainly a type of sea turtle (Gould, 1930), in this case, one attached to a group of shiny glass floats (France, 2017). And a 1925 sighting in the China Sea of "what seems to be a sea-snake swallowing a turtle" (Heuvelmans, 1968; Figure $2(c)$ ) is, as I have suggested (France, 2016b), a most "appropriate schematic should a T-shirt emblem ever be designed about entangled chelonians."

The present examination of the complete corpus of "sea serpent" anecdotes from the Western Pacific indicates sightings of putatively entangled animals to have been ubiquitous in this region. As shown in Table 2, the observed attributes of UMOs from the Western Pacific agree with those identified for the Gloucester UMO (France, 2019a) as well as for others from New England and Atlantic Canada (France, 2019c; France, 2020). The concordance shown between attributes described for the different sets of regional observations suggests a common explanation may apply to all. It is the present and parsimonious illation that these subsets of observed UMOs were entangled animals pulling trains of fishing gear or maritime debris, with the consequent physical and behavioral features displayed leading them to go unrecognized by eyewitnesses at the time, such that the mystery animals were deemed to have been sea serpents.

Capable of achieving respective lengths of 30 and 55 metres, the blue whale (Balaenoptera musculus) and the bootlace worm (Lineus longissimus) are the largest and longest animals known to have existed. However, neither of their body shapes can be invoked to explain the considerable lengths reported for the UMOs observed in the Western Pacific, which are of impossibly gargantuan proportions for all marine megafauna (McClain et al., 2015). Obviously, as there are no candidate animals that approach such lengths while maintaining extremely narrow bodies described as resembling those of snakes or eels, one has to look to a non-biological explanation. Only animals pulling long trains of entangled material of anthropogenic origin can account for the immensities observed.

Different from the case for North American UMOs, none of the anecdotes 


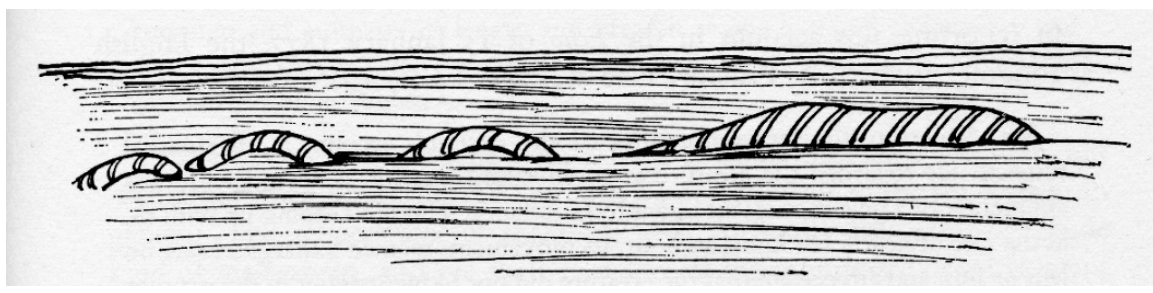

(a)
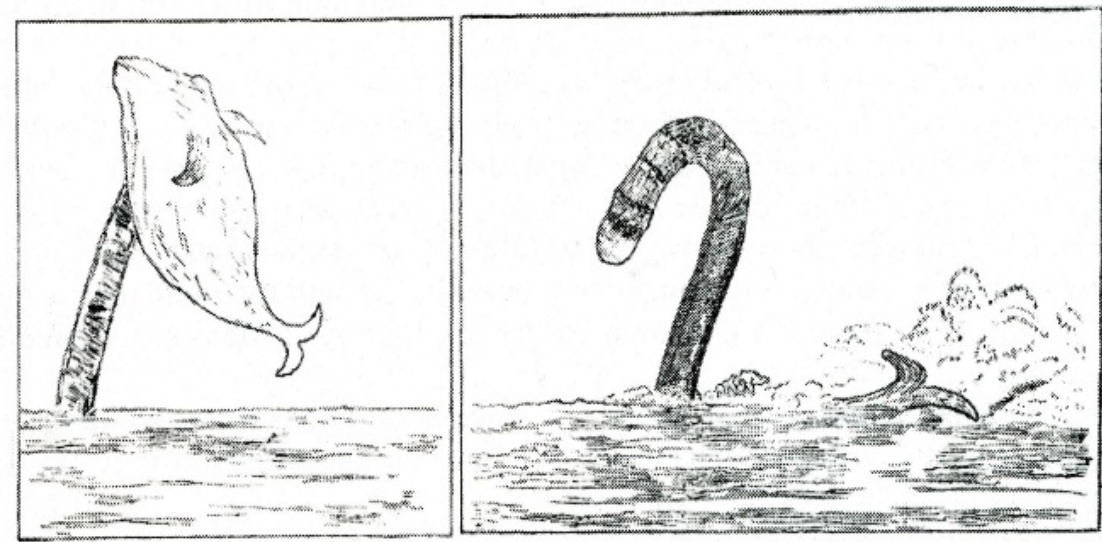

(b)

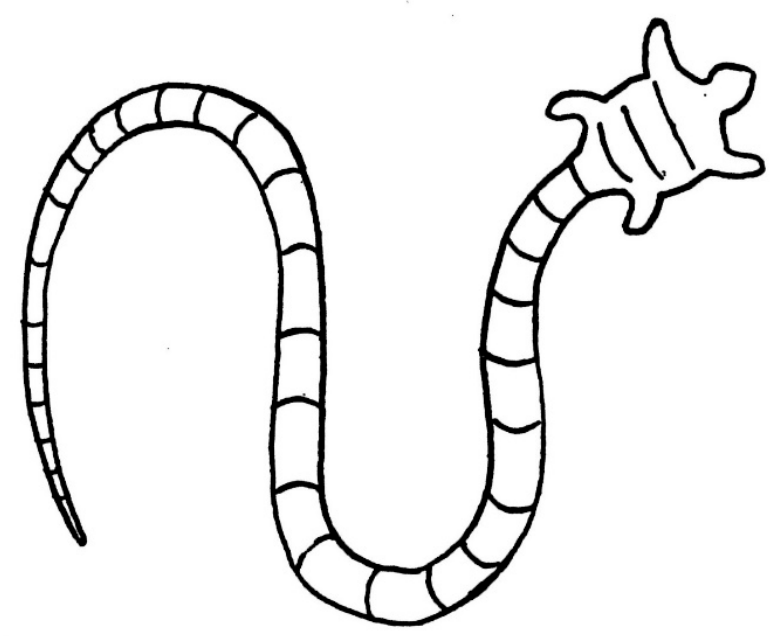

(c)

Figure 2. (a) Rear portion of an UMO observed in the Malacca Strait in 1876, and cryptozoologically believed to be the tail of a sea serpent (Heuvelmans, 1968) or alternatively and parsimoniously, to be an entangled train of fishing net material (France, 2016b); (b) Depictions of an encounter from the East China Sea in 1879 showing a purported sea serpent locked in battle with a whale (Heuvelmans, 1968) (left panel) or just a normal breaching whale with a thick line of debris entangled over its right fin, and (right panel) the same whale moments later heaving the entangled gear upward into the air while raising its tail to plunge back into the water (France, 2016a); (c) An UMO observed in 1925 in the China Sea and interpreted by cryptozoology as the "turtle-bodied snake" typology of sea serpent (Heuvelmans, 1968) or by conservation biology as a glaring example of an entangled chelonian (France, 2016b). (France, 2019a, from Heuvelmans, In the Wake of Sea-Serpents, 1968. Author's private collection.). 
concerning "sea serpents" in the West Pacific specifically likened the overall body to resembling a string of floats, kegs, or buoys attached to a fishing net (Table 2); regardless of Heuvelmans' later use of the expression "string-of-buoys sea-serpent" when referring to one such sighting. Nevertheless, some of the most telling evidence supporting the illation that these UMOs observed in the Western Pacific were mundane animals with the misfortune of being non-lethally entangled, comes from parsing descriptions of the physical attributes of the socalled body humps, hair, and scales.

Western Pacific UMOs resemble those from the Northwest Atlantic in being described as having bodies made up of serial components that denote entangled debris. Several anecdotes refer to barrel-sized bodies; another four describe bodies being covered with scales, one of which mentions barnacles of an impossibly large "soup-plate" size; and three anecdotes state the "smooth" scales "shone" "in the sun" "with green flashes." As previously mentioned, both barrels and glass-floats were customarily used for buoyancy in gillnets throughout the nineteenth century, an explanation which can be parsimoniously invoked for these accounts. And of course, as mentioned by Heuvelmans, horizontal scales on a vertically undulating body are a physical impossibility.

It is also not possible for the body of any animal noted for displaying a marked flexibility in terms of being able to "coil up on itself" to be composed of a series of humps, coils, loops, angular fins, or "impossible" arches that are actually elevated above the surface of the water, and have this rigid form of separated

Table 2. Observed physical and behavioral attributes of UMOs posited to have been entangled animals. Attributes are those used to describe the UMO observed in and around Gloucester in 1817, and clearly indicative of an animal entangled in marine debris (France, 2019a). Numbers shown indicate the incidence of occurrence for 28 different sightings in the Western Pacific between 1854 and 1962, 12 different Nova Scotian sightings between 1787 and 1939 (France, 2020), and 20 different sightings in New England between 1831 and 1925 (France, 2019c).

\begin{tabular}{|c|c|c|c|}
\hline Attribute & Western Pacific & Nova Scotia & New England \\
\hline Notable length & 20 & 11 & 9 \\
\hline Body composed of a series of irregular, jointed component parts (multiple humps, coils, or a ridge) & 15 & 7 & 9 \\
\hline Rapid speed of movement & 4 & 5 & 3 \\
\hline Notable flexibility of body & 1 & 3 & 1 \\
\hline Vertical undulating movement of body segments & 10 & 5 & 3 \\
\hline Body components likened to kegs or barrels, and sometimes scales or saucers & 6 & 8 & 2 \\
\hline Oblivious of surroundings or impervious to disturbance & 3 & 4 & 2 \\
\hline Overall body likened to a string of floats, kegs or buoys & 0 & 3 & 3 \\
\hline Obvious trailing wake or water disturbance & 6 & 6 & 2 \\
\hline Floating motionless, gently swaying in waves, or moving very slowly & 6 & 1 & 2 \\
\hline $\begin{array}{l}\text { Narrow, tapering, sinuous, snake/eel-like shape, often with absence of a } \\
\text { caudal fin or lateral appendages }\end{array}$ & 15 & 8 & 3 \\
\hline Extended body pulled down into water, thrown up into the air, or thrashed about on the surface & 3 & 0 & 1 \\
\hline Presence of a horn, spike, spine, mane, or other protuberance (sometimes identified as a head) & 9 & 3 & 2 \\
\hline
\end{tabular}


units and corresponding interstitial water be maintained when the animal submerges and remerges. Moreover, the remarkable fact that the body segments sometimes displayed a "spikey" or "saw-teeth" dorsal crest that looked like "an armoured hose" even when the animal was at rest proves the protrusions to not have been biological in nature. Furthermore, that manes of "hair" or long dangling "appendages" that "covered" UMOs were noted in three reports, bespeaks of the presence of entangled netting.

The mention made of rapid motion in UMOs from the Western Pacific is similar to observations from elsewhere (Table 2), and indicates a non-biological explanation for the observed elongated bodies. For, in the noted absence of lateral fins or caudal tails, animals with skinny serpentine bodies relying upon undulations for propulsion simply cannot generate the hydrodynamic forces necessary to achieve such fast movement. The agent of propulsion must therefore reside elsewhere, as for example, from an entangled animal at the front end of the debris train, which is either temporarily or permanently hidden beneath the surface. Streamlined body shapes have evolved in highly mobile marine animals to reduce as much drag as possible. That the motion of UMOs observed in the Western Pacific produced considerable water disturbance once again suggests a non-biological causality. Finally, the worm-like undulating motion remarked upon by many eyewitnesses took place in the vertical plane. This is diametrically opposite to the side-to-side propulsive contractions used by fish and serpents, but is in agreement with those of leeches and some marine mammals, neither the latter two of which, of course, have serpentine bodies of the sizes noted for the UMOs.

Observations that UMOs in the Western Pacific were sometimes seen resting motionless upon the surface suggests that the animals at the front end of the entangled train of fishing gear were probably large fish, as may have been the case for the Gloucester UMO (France, 2019a). Descriptions of what were imagined to be "heads" gazing about every which way are what barrel floats with attached flagpoles used to mark the ends of herring nets look like when swaying in the waves. As for the Gloucester UMO (France, 2019a), the report of a pointed "tongue" which "trembled" in the waves, was likely a marlin spike or fid, tools used by mariners for braiding together hemp ropes.

Western Pacific UMOs, like those in New England and Atlantic Canada, also displayed notable inattention to their surroundings and an imperviousness to physical assault (Table 2). Several eyewitnesses commented that the elongated series of humps came extremely close to ships, and in one case, the observed UMO was unresponsive to being struck by rifle shot, offering compelling evidence in the latter case that the long tail of that particular "sea serpent" must have been an inanimate artifact. Other anecdotes mention the tails of UMOs to be seen violently thrashing about on the surface. The sea serpent literature contains many so-described incidences; in some cases these have been interpreted as known animals locked in mortal combat with what were imagined to be sea serpents, but which can parsimoniously be explained as animals struggling to free 
themselves from entangled fishing gear, as has been frequently observed and emotionally described in modern times (e.g. Johnson, 2005). Remarkably, one anecdote reported that the long body of the UMO was seen to almost brush against the land. This is just the manner in how a long string of fishing net floats would respond to an onshore wind or series of breaking waves.

It might seem surprising that so many eyewitnesses could mistake entangled fishing gear for the body of a sea serpent. However, if one looks at nineteenthcentury fishery illustrations and photographs of long strings of casks on deployed gill nets (as shown in France, 2016a; France, 2019a; France, 2019b; France, 2020, or many online sources of historic images) it becomes obvious how the deception could easily arise. If seen at a distance, such float-lines, particularly if festooned with strands of matted netting or kelp, give an impression of solidity. Add to this the fact that the fishing gear would be observed bobbing along atop the surface of the water in an undulating motion, accompanied by much spray through being dragged behind an entangled animal, and it is no wonder that a conclusion was reached that a classic sea serpent was being glimpsed. For many in the nineteenth-century, be they the lay-public or natural scientists, there was no question that the seas in poorly explored regions of the planet-by which they meant, with the prevalent bias of the times, those remote from Europe-harboured such denizens of the deep (Sweeney, 1972; Westrum, 1979; Lyons, 2009; France, 2019a). Indeed, many examples exist of nineteenthcentury mariners and fishermen having experience in observing all manner of sea-life but whom were fooled by accumulations of anthropogenic debris and accompanying organic matter. One such example is an encounter with a fishing net from 1860 that occurred in the same region as the present investigation, and which was originally published in the journal The Zoologist (Oudemans, 1892: p. 350):

There was little wind, and the gentle ripples covered the surface of the sea... [when] my eye rested on a long dark object apparently making its way steadily through the water. After observing it some time in silence I was sorely puzzled and could make nothing of it. It was neither a seal nor a diver nor a fishing cormorant, for with their forms I was familiar; so I went on deck and consulted other eyes than mine. Sundry glasses were brought to bear on the suspicious object, and the general scrutiny seemed to decide that it was a large snake, about ten feet long (or much longer according to some), working its way vigorously against the tide by lateral undulations of the body. So strong was this conviction that the course of the ship was altered, and a boat got ready for lowering. With a couple of loaded revolvers, some boathooks and a fathom or so lead-line, I made ready for the encounter, intending to range up alongside, shoot the reptile through the head, make him fast by a clove-hitch, and tow him on board in triumph! By this time, however, a closer and more critical inspection had taken place, and the supposed sea-monster turned himself into a long dark root, gnarled and 
twisted, of a tree, secured to [i.e. entangled in] the moorings of a fishing net, with the strong tide passing it rapidly, and thus giving it an apparent life-like movement and serpentine aspect.

And in another case, it was not until the presumed "sea serpent" had been captured, hauled aboard, and closely examined, that the UMO was determined to be nothing more than a mass of netting and periphyton (France, 2019a).

Given the strength of engrained belief systems, both then and well as now (Dendle, 2006), it is not surprising that aquatic monsters can be conjured from the very ether itself (Lehn, 1979). For, as Loxton \& Prothero (2015: p. 233) astutely (and somewhat snidely) comment in their excoriation of cryptozoology, but do not elaborate upon further: "The problem, of course, is that such sightings [i.e. those they described as "a series of discrete coils, humps, or dark rounded objects ('like a string of buoys' is typical)," with the inference being "that they are connected beneath the water's surface"] are by their nature ambiguous: a humungous serpentine animal might resemble a string of buoys, but a group of smaller individual objects (say, an actual string of buoys) also might resemble a string of buoys."

Eyewitness testimonies can provide insight for recognizing baselines and gauging dynamics of change in both historical (Giglio et al., 2016; Lusher et al., 2018) and contemporary (Razafindrako et al., 2008; Liu et al., 2016; Barosa-Filho et al., 2020) fisheries. The present work posits the habitual early entanglement of marine life in the Western Pacific based on indirect evidence garnered through reinterpreting "sea serpent" sightings. Clearly entanglement has a prolonged antecedence and is not merely an epiphenomenon related to the modern-day advent and widespread use of plastic in the fishing industry. The prevalence of all purported sea serpent sightings that can be confidently deduced as having been entangled animals is about forty percent for the Western Pacific. This proportion is greater than those of less than fifteen percent and about twenty-five percent determined respectively for contemporaneous observations of UMOs from North America and the British Isles (France, 2019c; France, 2020; France, in prep.). The reason behind the comparatively higher value for the Western Pacific is beyond the bounds of this prefatory investigation, and will no doubt entail the further expertise of fisheries chroniclers (Butcher, 2004; Morgan \& Staples, 2006) and those familiar with the larger demographic and geographic maritime context of the region's complex environmental history (Boomgaard, 2007).

\section{Conflicts of Interest}

The author declares no conflicts of interest regarding the publication of this paper.

\section{References}

Aiken, W. R. G., \& Purser, J. (1936). The Preservation of Fibre Ropes for Use in Sea-Water. Plymouth Laboratory New Series, 20, 643-654. 
https://doi.org/10.1017/S0025315400058227

Al-Abdulrazzak, D., Naidoo, R., Palomares, M. L. D., \& Pauly, D. (2012). Gaining Perspective on What We've Lost: The Reliability of Encoded Anecdotes in Historical Ecology. PLoS ONE, 7, e43386. https://doi.org/10.1371/journal.pone.0043386

Alexander, K. E., Leavenworth, W. B., Willis, T. V., Hall, C. et al. (2017). Tambora and the Mackerel Year: Phenology and Fisheries during an Extreme Climate Event. Science Advances, 3, e1601635. https://doi.org/10.1126/sciadv.1601635

Alverson, D. L., Freeberg, M. H., Murawski, S. A., \& Pope, J. G. (1994). A Global Assessment of Fisheries Bycatch and Discards. Fisheries and Oceans Fisheries Technical Paper No. 339, Rome: FAO.

Anderson, A. (2013). The Antiquity of Sustained Offshore Fishing. Antiquity, 87, 879-885. https://doi.org/10.1017/S0003598X00049541

Anonymous (2019a). Dead Whale Was Tangled in Rope in East Lothian for "Months". BBC News 2019-04-25.

Anonymous (2019b). Whale Washed Up in Caithness Tangled in Canadian Fishing Gear. BBC News, 2019-06-03.

Bargnesi, F., Gridelli, S., Carrano, C., \& Ferretti, F. (2020). Reconstructing the History of the Sand Tiger Shark (Carcharias taurus) in the Mediterranean Sea. Aquatic Conservation: Marine and Freshwater Ecosystems, 30, 915-927. https://doi.org/10.1002/aqc.3301

Barosa-Filho, M., Seminara, C. I., Tavares, D. C., Siciliano, S., Hauser-Davis, R. A., \& Da Silva Mourao, J. (2020). Artisanal Fisher Perceptions on Ghost Nets in a Tropical South Atlantic Marine Biodiversity Hotspot: Challenges to Traditional Fishing Culture and Implications for Conservation Strategies. Ocean \& Coastal Management, 192, 105189. https://doi.org/10.1016/j.ocecoaman.2020.105189

Bauer, H. H. (2013). Cryptozoology and the Troubles with "Skeptics" and Mainstream Pundits. Journal of Scientific Exploration, 27, 690-704.

Bekker-Nielsen, T., \& Casola, D. B. (Eds.) (2010). Ancient Nets and Fishing Gear. Aarhus: Aarhus University Press.

Bolster, W. J. (2012). The Mortal Sea: Fishing the Atlantic in the Age of Sail. Cambridge, MA: Harvard University Press. https://doi.org/10.4159/harvard.9780674067219

Boomgaard, P. (2007). Southeast Asia: An Environmental History. Santa Barbara, CA: ABC-CLIO.

Boren, L., Morrissey, M., Muller, C. G., \& Gemmell, N. J. (2006). Entanglement of New Zealand Fur Seals in Man-Made Debris at Kaikoura, New Zealand. Marine Pollution Bulletin, 52, 442-446. https://doi.org/10.1016/j.marpolbul.2005.12.003

Brown, C. M. (1990). A Natural History of the Gloucester Sea Serpent: Knowledge, Power, and the Culture of Science in Antebellum America. American Quarterly, 42, 402-436. https://doi.org/10.2307/2712941

Burns, E. I. (2014). Monster on the Margin: The Sea Serpent Phenomenon in New England, 1817-1849. Ph. D. Thesis, Buffalo, NY: University of Buffalo.

Butcher, J. G. (2004). The Closing of the Frontier: A History of the Marine Fisheries of Southeast Asia, c.1850-2000. Singapore: Institute of Southeast Asian Studies. https://doi.org/10.1355/9789812305404

Cardamone, J. M. (2001). The Aging, Degradation, and Conservation of Historic Materials Made from Cellulosic Fibres. In J. M.Cardamone, \& M. T. Baker (Eds.), Historical Textiles, Papers, and Polymers in Museums (Chapter 2, pp. 8-22). Washington, DC: Washington Museum Publication. https://doi.org/10.1021/bk-2001-0779.ch002

Da Silva, T. C., Medeiros, P. M., Balcázar, A. L., De Sousa Araújo, T. A., Pirondo, A., \& 
Trindade Medeiros, M. F. (2014). Historical Ethnobiology: An Overview of Selected Studies. Ethnobiology and Conservation, 3, 1-12.

https://doi.org/10.15451/ec2014-6-3.4-1-12

Dearing, J. A., Acma, B., Bub, S., Chambers, F. M., Chen, X. et al. (2015). Social-Ecological Systems in the Anthropocene: The Need for Integrating Social and Biophysical Records at Regional Scales. The Anthropocene Review, 2, 220-246.

https://doi.org/10.1177/2053019615579128

Deedy, A. (2017). Hark! A Sea Monster! (Oh, No, Just a Dying Whale). All Those Strange Sea Monster Sightings in Days of Yore? This May be the Best Explanation Yet. Hakai Magazine, 2017-02-08.

Dendle, P. (2006). Cryptozoology in the Medieval and Modern Worlds. Folklore, 117, 190-206. https://doi.org/10.1080/00155870600707888

Derraik, J. G. B. (2002). The Pollution of the Marine Environment by Plastic Debris: A Review. Marine Pollution Bulletin, 42, 842-852. https://doi.org/10.1016/S0025-326X(02)00220-5

Dinsdale, T. (1966). The Leviathans. London: Routledge \& Kegan Paul.

Early-Capistran, M.-M., Sanez-Arroyo, A., Cardoso-Mohendano, J., Garibay-Melo, G. Peckham, S., \& Koch, V. (2018). Reconstructing 290 Years of Data-Poor Fishery Through Ethnographic and Archival Research: The East Pacific Green Turtle (Chelonia mydas) in Baja California, Mexico. Fish and Fisheries, 19, 57-77. https://doi.org/10.1111/faf.12236

Edyvane, K. S., \& Penny, S. S. (2017). Trends in Derelict Fishing Nets and Fishing Activity in Northern Australia: Implications for Trans-Boundary Fisheries Management in the Shared Arafura and Timor Seas. Fisheries Research, 188, 23-37.

https://doi.org/10.1016/j.fishres.2016.11.021

Engelhard, G. H., Thurston, R. H., Mackenzie, B. R., Alleway, H. K. et al. (2016). ICES Meets Marine Historical Ecology: Placing the History of Fish and Fisheries in Current Policy Context. ICES Journal of Marine Science, 73, 1386-1403. https://doi.org/10.1093/icesjms/fsv219

Fagan, B. (2017). Fishing: How the Sea Fed Civilization. New Haven, CT: Yale University Press.

France, R. L. (2016a). Reinterpreting Nineteenth-Century Accounts of Whales Battling 'Sea Serpents' as an Illation of Early Entanglement in Pre-Plastic Fishing Gear or Maritime Debris. International Journal of Maritime History, 28, 686-714. https://doi.org/10.1177/0843871416667434

France, R. (2016b). Historicity of Sea Turtles Misidentified as Sea Monsters: A Case for the Early Entanglement of Marine Chelonians in Pre-Plastic Fishing Nets and Maritime Debris. Coriolis: Interdisciplinary Journal of Maritime Studies, 6, 1-24.

France, R. L. (2017). Imaginary Sea Monsters and Real Environmental Threats: Reconsidering the Famous Osborne, "Moha-Moha", Valhalla, and "Soay Beast" Sightings of Unidentified Marine Objects. International Review of Environmental History, 3, 63-100. https://doi.org/10.22459/IREH.03.01.2017.07

France, R. L. (2018). Illustration of an 1857 "Sea Serpent" Sighting Reinterpreted as an Early Depiction of Cetacean Entanglement in Maritime Debris. Archives of Natural History, 45, 111-117. https://doi.org/10.3366/anh.2018.0486

France, R. L. (2019a). Disentangled: Ethnozoology and Environmental Explanation of the Gloucester Sea Serpent. Wageningen: Wageningen Academic Press. https://doi.org/10.3920/978-90-8686-886-5

France, R. L. (2019b). Ethnobiology and Shifting Baselines: An Example Reinterpreting 
the British Isles' Most Detailed Account of a Sea Serpent Sighting as Early Evidence for Pre-Plastic Entanglement of Basking Sharks. Ethnobiology and Conservation, 8, 1-31. https://doi.org/10.15451/ec2019-10-8.12-1-31

France, R. L. (2019c). Extreme Climatic Upheaval, Emergency Resource Adaptation, and the Emergence of Folkloric Belief: Geomythic Origin of Sea Serpents from Animals Becoming Entangled in Fishing Gear During New England's Nineteenth-Century Social-Ecological Crisis. Human Ecology, 47, 499-513.

https://doi.org/10.1007/s10745-019-00097-5

France, R. L. (2020). Early Entanglement of Nova Scotian Marine Animals in Pre-Plastic Fishing Gear or Maritime Debris: Indirect Evidence from Historic "Sea Serpent" Sightings. Proceedings of the Nova Scotian Institute of Science, 50, 319-349.

https://doi.org/10.15273/pnsis.v50i2.10004

Giglio, V. J., Luiz, O. J., Reis, M. S., \& Gerhardinger, L. C. (2016). Memories of Sawfish Fisheries in a Southwestern Atlantic Estuary. Traditional Marine Resource Management and Knowledge Information Bulletin, 36, 28-37.

Goode, G. B. et al. (1884). The Fisheries and Fishery Industries of the United States. National Oceanographic and Atmospheric Administration Reprinting. (Online Access, Numerous Sources)

Gould, R. T. (1930). The Case for the Sea-Serpent. London: Philip Allen Publishers.

Gregory, M. R. (2009). Environmental Implications of Plastic Debris in Marine Settings-Entanglement, Ingestion, Smothering, Hangers-On, Hitch-Hiking and Alien Invasions. Philosophical Transactions of the Royal Society B, 364, 2013-2025. https://doi.org/10.1098/rstb.2008.0265

Groom, C. J., \& Coughran, D. K. (2012). Entanglements of Baleen Whales off the Coast of Western Australia Between 1982 and 2010: Patterns of Occurrence, Outcomes and Management Responses. Pacific Conservation Biology, 18, 203-214. https://doi.org/10.1071/PC130203

Heuvelmans, B. (1968). In the Wake of the Sea-Serpents. New York: Hill and Wang.

Jaaman, S. A., Lah-Anyi, Y. U., \& Pierce, G. J. (2009). The Magnitude and Sustainability of Marine Mammal By-Catch in Fisheries in East Malaysia. Journal of the Marine Biological Association of the United Kingdom, 89, 907-920. https://doi.org/10.1017/S002531540800249X

Johannes, R. E., \& Neis, B. (2007). The Value of Anecdote. In N. Haggan, B. Neis, \& I. G. Baird (Eds.), Fishers Knowledge in Fisheries Science and Management (pp. 41-58). Paris: UNESCO.

Johnson, T. (2005). Entanglements: The Intertwined Fates of Whales and Fishermen. Gainesville, FL: University Press of Florida.

Klaer, N. L. (2001). Stream Trawl Catches from South-Eastern Australia from 1918 to 1957: Trends in Catch Rates and Species Composition. Marine and Freshwater Research, 52, 399-410. https://doi.org/10.1071/MF00101

Kristjonsson, H. (1971). Modern Fishing Gear of the World 3: Fishing Gear, Purse Seining, Aimed Trawling. Rome: Food and Agriculture Organization.

Kuang-Ti, L. (2001). Prehistoric Marine Fishing Adaptation in Southern Taiwan. Journal of East Asian Archaeology, 3, 47-74. https://doi.org/10.1163/156852301100402769

Laist, D. W. (1997). Impacts of Marine Debris: Entanglement of Marine Life in Marine Debris Including a Comprehensive List of Species with Entanglement and Ingestion Records. In J. M. Coe, \& D. B. Rogers (Eds.), Marine Debris: Sources, Impacts and Solutions (pp. 99-139). New York: Springer. 
https://doi.org/10.1007/978-1-4613-8486-1_10

Lehn, W. H. (1979). Atmospheric Refraction and Lake Monsters. Science, 205, 183-185. https://doi.org/10.1126/science.205.4402.183

Liu, M., Lin, M. Turvey, S. T., \& Li, S. (2016). Fishers' Knowledge as an Information Source to Investigate Bycatch of Marine Mammals in the South China Sea. Animal Conservation, 20, 182-192. https://doi.org/10.1111/acv.12304

Loxton, D., \& Prothero, D. R. (2015). Abominable Science!: Yeti, Nessie, and Other Famous Cryptids. New York: Columbia University Press.

Lusher, A. L., Hernandez-Milan, G., Berrow, S., Rogan, E., \& O’Connor, I. (2018). Incidence of Marine Debris in Cetaceans Stranded and Bycaught in Ireland: Recent Findings and a Review of Historical Knowledge. Environmental Pollution, 232, 467-476. https://doi.org/10.1016/j.envpol.2017.09.070

Lyons, S. L. (2009). Species, Serpents, Spirits, and Skulls: Science at the Margins in the Victorian Age. New York: State University of New York Press.

Maschner, H. D. G., Trits, A. W., Reedy-Maschner, K. L., \& Bretts, M. (2014). The Decline of Steller Sea Lions (Eumetopias jubatus) in the North Pacific: Insights from Indigenous People, Ethnohistoric Records and Archaeological Data. Fish and Fisheries, 15, 634-660. https://doi.org/10.1111/faf.12038

Mccaskill, J. (2009). Conserving Waterlogged Rope: A Review of Traditional Methods and Experimental Research with Polyethylene Glycol. MA Thesis, College Station, TX: Texas A\&M University.

McClain, C. R., Balk, M. A. et al. (2015). Sizing Ocean Giants: Patterns of Intraspecific Size Variation in Marine Megafauna. PeerJ, 2, E715. https://doi.org/10.7717/peerj.715

Mcclenachan, L., Ferretti, F., \& Baum, J. K. (2012). From Archives to Conservation: Why Historical Data are Needed to Set Baselines for Marine Animals and Ecosystems. Conservations Letters, 5, 349-359. https://doi.org/10.1111/j.1755-263X.2012.00253.x

Meine, C. (1999) It's about Time: Conservation Biology and History. Conservation Biology, 13, 1-3. https://doi.org/10.1046/j.1523-1739.1999.013001001.x

Morgan, G. R., \& Staples, D. J. (2006). The History of Industrial Marine Fisheries in Southeast Asia. Regional Office for Asia and the Pacific Publication 2006/12. Food and Agriculture Organization of the United Nations.

National Oceanic and Atmospheric Administration (NOAA) (2014). Report on the Entanglement of Marine Species in Marine Debris with an Emphasis on Species in the United States. Silver Spring, MD: National Oceanic and Atmospheric Administration Marine Debris Program

Neilson, J. L., Straley J. M., Gabriele, C. M., \&. Hills, S. (2009). Non-Lethal Entanglement of Humpback Whales (Megaptera novaangliae) in Fishing Gear in Northern Southeast Alaska. Journal of Biogeography, 36, 452-464. https://doi.org/10.1111/j.1365-2699.2007.01820.x

Nelms, S. E., Duncan, E. M., Broderick, A. C., Galloway, T. S., Godfrey, M. H. et al. (2015). Plastic and Marine Turtles: A Review and Call for Research. ICES Journal of Marine Science, 73, 165-181. https://doi.org/10.1093/icesjms/fsv165

Novaglio, C., Smith, A., Frusher, S., \& Ferretti, F. (2020). Identifying Historical Baseline at the Onset of Exploitation to Improve Understanding of Fishing Impacts. Aquatic Conservation: Marine and Freshwater Ecosystems, 30, 475-485. https://doi.org/10.1002/aqc.3264

O’Connor, S., Ono, R., \& Clarkson, C. (2011). Pelagic Fishing at 42,000 Years Before the Present and the Maritime Skills of Modern Humans. Science, 6059, 1117-1121. 
https://doi.org/10.1126/science.1207703

O’Neill, J. P. (1999). The Great New England Sea Serpent: An Account of Unknown Creatures Sighted by Many Respectable Persons Between 1638 and the Present Day. Camden: Down East Books.

Ono, R., \& Intoch, M. (2011). Island of Pelagic Fishermen: Temporal Changes in Prehistoric Fishing on Fais, Micronesia. The Journal of Island and Coastal Archaeology, 6, 255-286. https://doi.org/10.1080/15564894.2010.540531

Oudemans, A. C. (1892). The Great Sea-Serpent. Greenville, OH: Coachwhip Publications. (2007 Facsimile Reprinting)

Parsons, E. C. M. (2004). Sea Monsters and Mermaids in Scottish Folklore: Can These Tales Give Us Information on the Historic Occurrence of Marine Animals in Scotland? Anthrozoös, 17, 73-80. https://doi.org/10.2752/089279304786991936

Pauly, D. (1995). Anecdotes and the Shifting Baseline Syndrome of Fisheries. Trends in Ecology and Evolution, 10, 430. https://doi.org/10.1016/S0169-5347(00)89171-5

Paxton, C. G. M. (2009). The Plural of “Anecdote" Can Be "Data”: Statistical Analysis of Viewing Distances in Reports of Unidentified Large Marine Animals 1758-2000. Journal of Zoology, 279, 381-387. https://doi.org/10.1111/j.1469-7998.2009.00630.x

Paxton, C. G. M., \& Naish, D. (2019). Did Nineteenth Century Marine Vertebrate Fossil Discoveries Influence Sea Serpent Reports? Earth Sciences History, 38, 16-27.

https://doi.org/10.17704/1944-6178-38.1.16

Razafindrako, Y., Andrianarivelo, N., Cerchio, S., Rasoamananto, I., \& Rosenblaum, H. (2008). Preliminary Assessment of Cetacean Incidental Mortality in Artisanal Fisheries in Anako, Southwester Region of Madagascar. Western Indian Ocean Journal of Marine Science, 7, 175-184. https://doi.org/10.4314/wiojms.v7i2.48275

Reeves, R. R., Mcclellan, K., \& Werner, T. B. (2013). Marine Mammal Bycatch in Gillnet and Other Entangling Net Fisheries, 1990 to 2011. Endangered Species Research, 20, 71-97. https://doi.org/10.3354/esr00481

Richards, A. H. (1994). Problems of Drift-Net Fisheries in the South Pacific. Marine PolIution Bulletin, 29, 106-111. https://doi.org/10.1016/0025-326X(94)90433-2

Saenz-Arroyo, A., Roberts, C. M., Torre, J., \& Carino-Olvera, M. (2005). Using Fishers' Anecdotes, Naturalists' Observations and Grey Literature to Reassess Marine Species at Risk: The Case of the Gulf Grouper in the Gulf of California, Mexico. Fish and Fisheries, 6, 121-133. https://doi.org/10.1111/j.1467-2979.2005.00185.x

Saenz-Arroyo, A., Roberts, C. M., Torre, J., Carino-Olvera, M., \& Hawkins, J. P. (2006). The Value of Evidence about Past Abundance: Marine Fauna of the Gulf of California through the Eyes of 16th to 19th Century Travellers. Fish and Fisheries, 7, 128-146.

https://doi.org/10.1111/j.1467-2979.2006.00214.x

Schwerdtner Manez, K., Holm, P., Blight, L., Coll, M., Macdiarmid, A. et al. (2014). The Future of Oceans Past: Towards a Global Marine Historical Research Initiative. Plos ONE, 9, e101466. https://doi.org/10.1371/journal.pone.0101466

Soini, W. (2010). Gloucester's Sea Serpent. The History Press.

Sweeney, J. B. (1972). A Pictorial History of Sea Monsters and Other Dangerous Marine Life. New York: Nelson-Crown.

Szabo, P., \& Hedl, R. (2011). Advancing the Integration of History and Ecology for Conservation. Conservation Biology, 25, 680-687. https://doi.org/10.1111/j.1523-1739.2011.01710.x

Tilzey, R. D. J., \& Rowling, K. R. (2001). History of Australia's South East Fishery: A Scientist's Perspective. Marine and Freshwater Research, 52, 361-375. 
https://doi.org/10.1071/MF99185

Tulloch, V., Pirotta, V., Grech, A., Crocetti, S., Double, M. et al. (2019). Long-Term Trends and a Risk Analysis of Cetacean Entanglements and Bycatch in Fisheries Gear in Australian Waters. Biodiversity and Conservation, 29, 251-282. https://doi.org/10.1007/s10531-019-01881-X

Vegter, A. C., Barletta, M., Beck, C., Borrero, J., Burton, H., Campbell, M. L. et al. (2014). Global Research Priorities to Mitigate Plastic Pollution Impacts on Marine Wildlife. Endangered Species Research, 25, 225-247. https://doi.org/10.3354/esr00623

Wabnitz, C., \& Nicols, W. J. (2010). Plastic Pollution: An Ocean Emergency. Marine Turtle Newsletter, 129, 1-4.

Westrum, R. (1979). Knowledge about Sea-Serpents. In R. Wallis (Ed.), On the Margins of Science: The Social Construction of Rejected Knowledge (pp. 293-314). Keele: University of Keele Press. https://doi.org/10.1111/j.1467-954X.1979.tb00066.x

Wilcocks, J. C. (1884). The Sea-Fisherman, Comprising the Chief Methods of Hook and Line Fishing in the Seas, and Remarks on Nets, Boats, and Boating (4th ed.). London: Longmans, Green, and Co. https://doi.org/10.5962/bhl.title.31948

Wilcox, C., Heathcote, G., Goldberg, J., Gunn, R., Peel, D., \& Hardesty B. D. (2014). Understanding the Sources and Effects of Abandoned, Lost, and Discarded Fishing Gear on Marine Turtles in Northern Australia. Conservation Biology, 29, 198-206. https://doi.org/10.1111/cobi.12355

Wright, A., \& Doulman, D. J. (1991). Drift-Net Fishing in the South Pacific: From Controversy to Management. Marine Policy, 15, 303-337.

https://doi.org/10.1016/0308-597X(91)90081-L 